\title{
Rancang Bangun Kontrol Pintu Air Dan Monitoring Ketinggian Air Sungai Berbasis Internet of Things (IoT)
}

\author{
Gilang Mahendra ${ }^{1}$, Sukardi ${ }^{2}$ \\ ${ }^{1}$ Universitas Negeri Padang \\ Jl.Prof. Dr. Hamka, Air Tawar Padang, 35132, Indonesia \\ gilangmahendra35@gmail.com ${ }^{1}$, sukardiunp@ft.unp.ac.id ${ }^{2}$
}

\begin{abstract}
Floods that often occur in Indonesia often cause casualties due to the absence of early warnings given to residents living near the river flow, as well as the frequent implementation of negligence by the sluice gates to control manual floodgates. The research objective in this final project is to create a design tool for water gate control and river water level monitoring based on internet of things (IoT), where the door supervisor no longer needs to open the door manually so that the negligent officers can be minimized and the residents around the river can be alert to conditions. rivers and prepare for flooding. Methods in designing tools include block diagrams, flowcharts, then mechanical design, and software design, mechanical design is made of a miniature dam and for designing software used by the Arduino IDE application to build a program, as a data center and control using NodeMCU . From the test results it can be denied that when the supply is turned on the ultrasonic sensor will read the air level, if it reaches a certain height, the NodeMCU microcontroller will send an altitude status and standby 1 or 4 on the Telegram application. In the first reservoir when the water level reaches $12 \mathrm{~cm}$, the servo motor will open $45^{\circ}$ and the door is half open and sends the Alert 4 status and then if the air has reached the threshold, the height of the servo motor is $17 \mathrm{~cm}$, it will open the door $90^{\circ}$ or all. then the water will flow to the next shelter and send a notification to Telegram, namely Alert 3.In the second reservoir, the air flow that has reached $12 \mathrm{~cm}$, the motor will open $45^{\circ}$, then the door is open half the water will flow to the last shelter and if the air flow has exceeded the $16 \mathrm{~cm}$ limit the door will open. The ultrasonic sensor works with a high degree of accuracy so that there is no error when reading it. The message will be received from 5 seconds depending on the internet connection, the reading in the application is the water level status, as well as the 1 and 4 standby status which will be processed by NodeMCU and then continue to be an appeal on the Telegram application.
\end{abstract}

\section{Keywords-Ultasonic Sensor, NodeMCU ESP8266, Internet of Things (IoT), Telegram.}

Abstrak - Musibah banjir yang sering terjadi di indonesia sering kali memakan korban jiwa dikarenakan tidak adanya peringatan dini yang diberikan kepada penduduk yang bermukim di sekitaran aliran sungai, serta sering terjadinya kelalaian dari petugas pintu air untuk mengotrol pintu air secara manual. Tujuan penelitian pada tugas akhir ini untuk membuat sebuah alat rancang bangun kontrol pintu air dan monitoring ketinggian air sungai berbasis internet of things (IoT)yang dimana pengawas pintu air tidak perlu lagi mengatur pintu secara manual sehingga kelalaian petugas dapat di minimalisirkan dan penduduk sekitran sungai dapat mengetahui kondisi ketinggian sungai dan mempersiapkan diri sebelum terjadinya banjir. Metode pada perancangan alat meliputi pada diagram blok, flowchart, kemudian perancangan mekanik, dan perancangan software, pada perancangan mekanik dibuat sebuah miniatur bendungan serta untuk perancangan software digunakan aplikasi arduino IDE untuk membangun sebuah program, sebagai pusat data dan kontrol mengunakan NodeMCU. Dari hasil pengujian dapat disimpulkan bahwa pada saat supply di hidupkan sensor ultrasonik akan membaca ketinggian air, jika mencapai pada tinggi tertentu maka mikrokontroler NodeMCU akan mengirim status ketinggian serta siaga 1 atau 4 pada aplikasi Telegram. Pada penampungan pertama ketika ketinggian air mencapai $10 \mathrm{~cm}$, motor servo akan membuka $45^{\circ}$ dan pintu terbuka setengah serta mengirimkan status Siaga 4 dan kemudian jika air sudah mencapai ambang batas yaitu ketinggian $17 \mathrm{~cm}$ motor servo akan membuka pintu $90^{\circ}$ atau seluruhnya maka air akan mengalir ke penampungan selanjutnya dan mengirimkan notifikasi pada Telegram yaitu Siaga 3. Di penampungan kedua, debit air yang sudah mencapai $12 \mathrm{~cm}$ motor akan terbuka $45^{\circ}$ maka pintu terbuka setengah air akan mengalir ke penampungan terakhir serta jika debit air sudah melebihi batas $16 \mathrm{~cm}$, pintu akan terbuka sepenuhnya. Sensor ultrasonik bekerja dengan tingkat akurasi yang tinggi sehingga tidak terjadi kesalahan saat pembacaannya. Pesan akan diterima kurang dari 5 detik tergantung pada koneksi internet, pembacaan yang ada pada aplikasi adalah status ketinggian air, serta status siaga 1 dan 4 yang akan di olah oleh NodeMCU dan kemudian di teruskan menjadi himbauan pada aplikasi Telegram.

Kata kunci-Sensor Ultrasonik, NodeMCU ESP8266, Internet of Things ( IoT), Telegram. 


\section{Pendahuluan}

Musibah banjir yang kerap berlangsung di Indonesia berakibat langsung pada daerah yang berada di sekitar aliran sungai. Pada saat masa penghujan, banyak kawasan penduduk, perkebunan maupun pertanian yang menghadapi kebanjiran. Sehingga dari itu perlunya dibangun sesuatu sistem pengendalian air agar meminimlisir dampak akibat dari banjir. Salah satu metode untuk menahan debit air yaitu dengan membuat isntalasi bendungan ataupun waduk.

Bendungan merupakan konstruksi yang dibentuk agar mengurangi laju air dengan cara membangun sebuah tembok pada suatu aliran sungai. Mayoritas bendungan pula mempunyai bagian pintu air yang berperan membuang air yang berlebihan secara bertahap ataupun berkepanjangan sesuai dengan kondisi debit atau volume air yang terdapat pada bendungan tersebut[1]

Umumnya bendungan memiliki pintu air yang berfungsi untuk mengotrol volume debit air dengan bertahap, dan sebaiknya pintu air tersebut tidak di kontrol secara manual untuk menghindari kelalaian dari petugas pintu air. Maka dari itu untuk mengatasi masalah tersebut dibutuhkan suatu alat yang bisa membaca ketinggian air serta dapat mengendalikan pintu air secara otomatis.

Dengan perkembangan zaman saat ini peringatan dini banjir harus mempermudah masyarakat supaya bisa mengatisipasi banjir dengan cepat. Beberapa penelitian sebelumnya mengkaji tentang sistem peringatan dini banjir dengan menggunakan sensor ultrasonik dan mikrokontroller dengan media informasi berbasis sms gateway. [2]

Dalam memberikan informasi yang tergolong darurat, sistem monitoring harusnya bisa dikases dengan gampang, sangat cepat, dimana saja, serta kapan saja dan perlu terdapatnya sebuah peringatan dini yang bisa menginformasikan kepada warga jika volume air sudah melebihi batas, supaya warga bisa mempersiapkan diri untuk menghadapi dampak dari banjir. [3]

Dari latar belakang masalah yang telah diuraikan di atas dapat di identifikasikan permasalahan sebagai berikut Sistem yang menggunakan SMS hanya memberi peringatan seperti status SIAGA III, SIAGA II dan SIAGA I dalam komunikasi bluetooth hanya bisa dilakukan dalam jarak dekat belum adanya penerapan mengenakan sistem Internet of Things (IoT]. [4] Adapun tujuan yang diinginkan dan di capai dalam penulisan proyek akhir ini adalah sebagai berikut Merancang perangkat keras untuk pengontrolan pintu air pada bendungan secara otomatis membuat program untuk sitem monitoring level ketinggian air pada android melakukan pengujian pengontrolan pintu air yang dibuat.

\section{Sensor Ultrasonik}

Sensor Ultrasonik yang digunakan sebagai sensor jarak adalah HC-SR04 sensor ini memanfaatkan gelombang ultrasonik di mana keluaran dari sensor ini berupa sinyal digital sensor terdiri atas 4 pin.

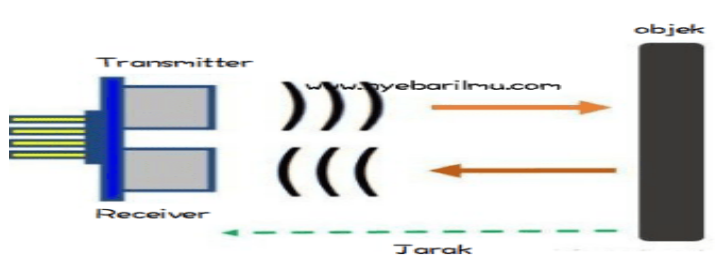

Gambar 1. Cara Kerja Sensor Ultrasonik

Berikut adalah konfigurasi pin dari Ultrasonik HC-SR04 yang dapat dilihat pada Tabel 1 di bawah ini.

Tabel 1. Konfigurasi Pada Sensor Ultrasonik

\begin{tabular}{|c|c|c|}
\hline No & PIN & Keterangan \\
\hline 1 & 1 & Vcc $(+5 \mathrm{~V})$ \\
\hline 2 & 2 & Trigger \\
\hline 3 & 3 & Echo \\
\hline 4 & 4 & Ground \\
\hline
\end{tabular}

\section{Motor Servo}

" Motor Servo merupakan suatu fitur ataupun aktuator putar yang dibangun dengan sistem yaitu kontrol umpan balik loop tertutup, agar bisa di set- up ataupun di atur untuk memastikan serta menentukan posisi pada sudut sumbu dari output motor. berikut ini bagian dari motor servo terdiri dari sebuah motor DC, kemudian beberapa susunan gear, susunan kontrol serta potensiometer. [5]

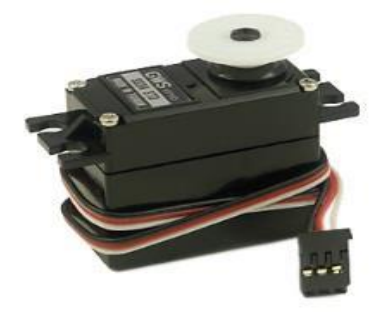

Gambar 2. Motor Servo

(Sumber : Randi Yusuf N , 2015)

Penjelasan mudahnya seperti ini, beberapa bagian motor servo yaitu motor DC, susunan gear, susunan kontrol dan potensiometer, motor servo yang digunakan memiliki masukan $5 \mathrm{~V}$ dan memiliki putaran maksimal $180^{\circ}$ dan yang digunakan jenis tipe gear plastik.

Posisi sumbu output kemudian di sensor agar ditemukan posisi sumbu sudah betul atau belum seperti diharapkan, serta jika belum, kontrol input tersebut mengirimkan sinyal kendali agar posisi sumbu tersebut tepat dengan posisi yang diharapkan oleh pengguna. Untuk menggerakkanya dapat di atur dengan lebar pulsa 
yang dikirimkan pada kontroler motor tersebut yang berupa sinyal PWM.

\section{Telegram}

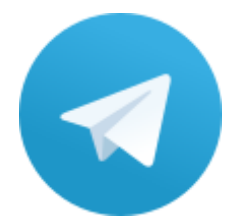

\section{Gambar 3. Logo Telegram}

(Sumber : Telegram.org)

Telegram merupakan suatu aplikasi perpesanan gratis yang berfokus pada kecepatan dan keamanan, aplikasi pengirim pesan praktis ini berbasis cloud. Merujuk pada Website resmi Telegram, Telegram sendiri tersedia bagi semua jenis smartphone baik itu Android (4.1 hingga yang terbaru), IOS (9.0 dan ke atas ) serta aplikasi macOS yang asli dan seluruh aplikasi dekstop baik itu Windows, macOS, serta Linux.

Dengan menggunakan Telegram pengguna bisa mengirim pesan, foto, berbagai tipe file (doc, zip, mp3, etc) serta juga bisa mengirim video, Telegram juga mendukung enskripsi end-to-end untuk video call, dan audio serta juga mendukung pesan voice chat pada grub untuk ribuan pengguna dan yang jelas ini semua adalah gratis. Beragam kelebihan yang telah ditawarkan pasti sangat berperan terhadap penelitian ini dan dengan adanya cloud yang tertanam di dalam server aplikasi Telegram dimana diizinkan menyimpan informasi - informasi semacam percakapan, foto, audio, serta video( Sutikno, Handayani, Stiawan, Riyadi,\&amp;amp; Subroto, 2016). [6]

Pengunaan bot yang tersedia pada Telegram memiliki kecerdasan artifisial di mana terdapat fitur bot yang dapat terhubung melalui internet dan dapat terintegrasi dengan berbagai layanan. melalui fitur ini penulis bermaskud membangun suatu sistem yang dapat tersambung antara Telegram dan sistem pegontrolan pintu air. .

\section{Pemograman Pada Mikrokontroler NodeMCU}

Suatu mikrokontroler tidak bisa berfungsi apabila tidak dimasukkan suatu program yang di instalkan pada Mikrokontroler tersebut. Oleh sebab itu, dalam perancangan dan pembuatan pemograman untuk Tugas Akhir maka digunakan suatu perangkat lunak selaku media untuk menghubungkan program list yang hendak di instalkan ke dalam Mikrokontroler NodeMCU dengan memanfaatkan Aplikasi Arduino (IDE). [7]

IDE ialah singkatan daripada Integrated Developtment Enviroenment, ataupun apabila di artikan ke dalam Bahasa Indonesia ialah area terintegrasi yang dimanfaatkan untuk melangsungkan sebuah pengembangan. Mengapa disebut seperti area atau lingkungan di karenakan menggunakan aplikasi ini
Arduino dimasukkan sebuah program untuk melakukan beberapa fungsi yang di instalkan lewat sintaks pada pemograman. Arduino mempunyai Bahasa pemogramannya sendiri yang dapat menyamai Bahasa pemograman C. [8] Bahasa pemograman pada Arduino (sketch) telah dilakukan modifikasi agar mempermudah pendatang baru dalam melaksanakan pemograman dari bahasa orisinilnya.

\section{NodeMCU ESP8266}

NodeMCU ialah mikrokontroler yang sudah terintegrasi dengan materi Wi- Fi serta terhitung kategori ESP8266, jenis yang digunakan ialah ESP- 12E berbasis firmware yitu eLua. Pada NodeMCU pula telah dilengkapi dua buah tombol antara lain reset, flash, serta mempunyai regulator 3. 3V dengan tipe AMS1117 supaya sanggup bekerja pada tegangan yang mempunyai masukan dengan besar hingga 5V lebih. [9] NodeMCU memakai bahasa pemograman yaitu eLua yang ialah paket dari materi ESP8266.

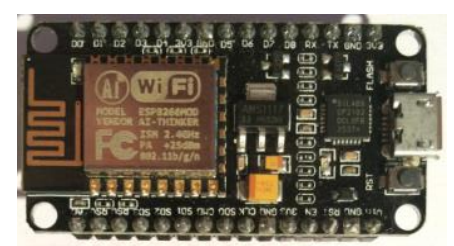

Gambar 4. NodeMCU ESP-12E

Tabel 2. Spesifikasi NodeMCU ESP8266

\begin{tabular}{|c|c|c|}
\hline \multirow{2}{*}{ Spesifikasi } & \multicolumn{2}{|c|}{ Versi NodeMCU } \\
\cline { 2 - 3 } & Versi 0.9 & Versi 1.0 \\
\hline $\begin{array}{c}\text { Vendor } \\
\text { Pembuat }\end{array}$ & Amica & Amica \\
\hline Tipe ESP8266 & ESP12 & ESP-12E \\
\hline USB Port & Micro USB & Micro USB \\
\hline GPIO Pin & 11 & 11 \\
\hline ADC & 1 Pin (10 bit) & 1 Pin (10 bit) \\
\hline $\begin{array}{c}\text { Usb to Serial } \\
\text { Converter }\end{array}$ & CH340G & CP2102 \\
\hline Power Input & $5 \mathrm{Vdc}$ & $5 \mathrm{Vdc}$ \\
\hline Ukuran Module & $47 \times 31 \mathrm{~mm}$ & $47 \times 24 \mathrm{~mm}$ \\
\hline
\end{tabular}

NodeMCU dikembangkan Perusahaan Amica serta mikrokontroler ini pula bisa diprogram lewat Arduino IDE dengan libary esp8266, sehingga bisa dengan gampang diprogram menggunakan bahasa pemograman pada Arduino IDE dan digunakan membangun sebuah projek IoT. 


\section{Internet of Things (IoT)}

IoT ialah sistem di mana beberapa objek dapat saling terhubung lewat jaringan internet. Sistem pengoperasian pada IoT dirancang agar dapat memerintahkan objek yang sudah terhubung, dengan metode yang sangat efektif. Pada konteks keahlian autonomic pada skala besar dalam sistem IoT yang sangat kompleks ini, pengoptimalan serta pengatahuan dalam aspek tertentu masing- masing komponen sangat diperlukan. Keamanan informasi pribadi memiliki kedudukan berarti sebab sistem IoT ini berurusan dengan data pribadi serta keamanan yang sangat krusial. IoT bisa mencakup seluruh bidang yaitu keamanan, data pribadi, jasa, arsitektur, usaha, serta sistem manajemen dan lainnya. [10]

\section{METODE}

\section{Blok Diagram}

Perancangan blok diagram dalam penelitian ini bertujuan untuk memudahkan dalam proses perancangan alat, perancangan mekanik, serta memudahkan dalam proses analisa. Perancangan dilakukan dengan membuat blok diagram, serta membuat sistem kerja alat. Pada Gambar 1dapat dilihat bentuk diagram blok sistem yang telah dirancang, masing-masing blok diagram memiliki fungsi yang berbeda-beda pada sistem kerja alat yang akan dibuat.

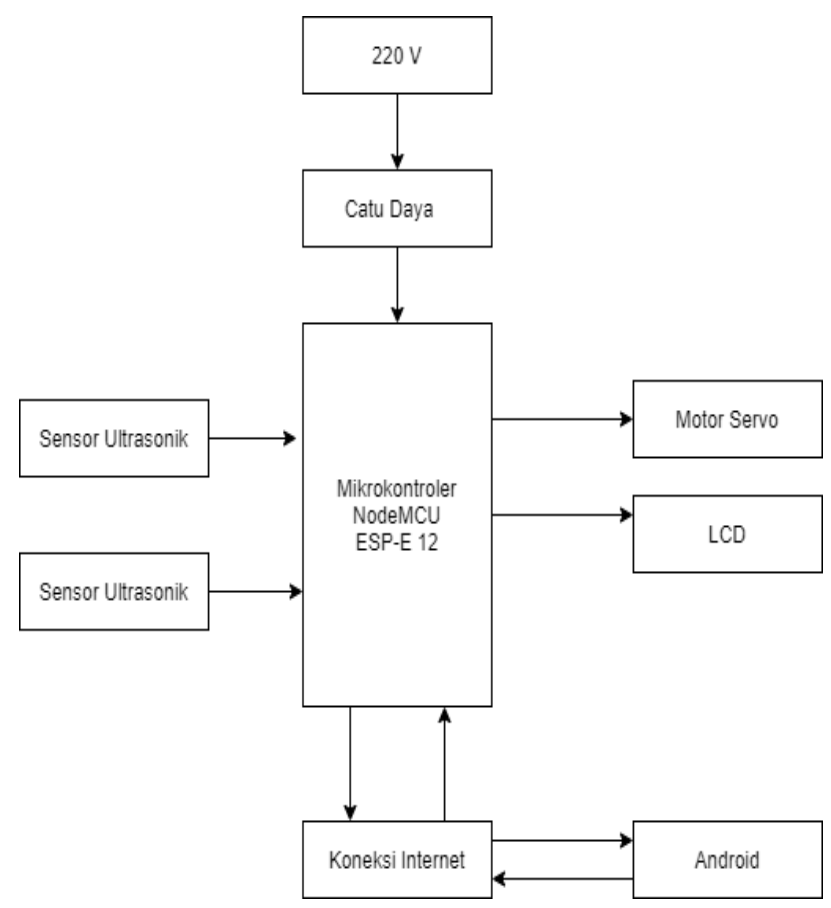

Gambar 5. Blok Diagram Sistem

Berdasarkan gambar di atas peran dari blok diagram di atas sebagai berikut: a. Catu daya digunakan untuk menyuplai tegangan kepada seluruh rangkaian.

b. Mikrokontroler NodeMCU sebagai pusat kendali dan pengolahan data..

c. Sensor Ultrasonik sebagai sensor jarak untuk mengukur level ketinggian air.

d. Motor Servo berfungsi sebagai pembuka dan penutup pintu bendungan.

e. Koneksi Internet berfungsi sebagai penghubung antara NodeMCU dan Telegram atau aplikasi android.

f. Aplikasi Android menunjukkan tampilan siaga dan status ketinggian air.

\section{Flowchart}

Flowchart berperan sebagai penunjuk untuk membentuk listing program, Flowchart juga dapat menunjukan arahan pada program yang akan dibuat. Secara garis besar flowchart diagram sistem ini akan memudahkan untuk melihat alur perancangan, agar lebih jelas bisa dilihat pada gambar 6 .

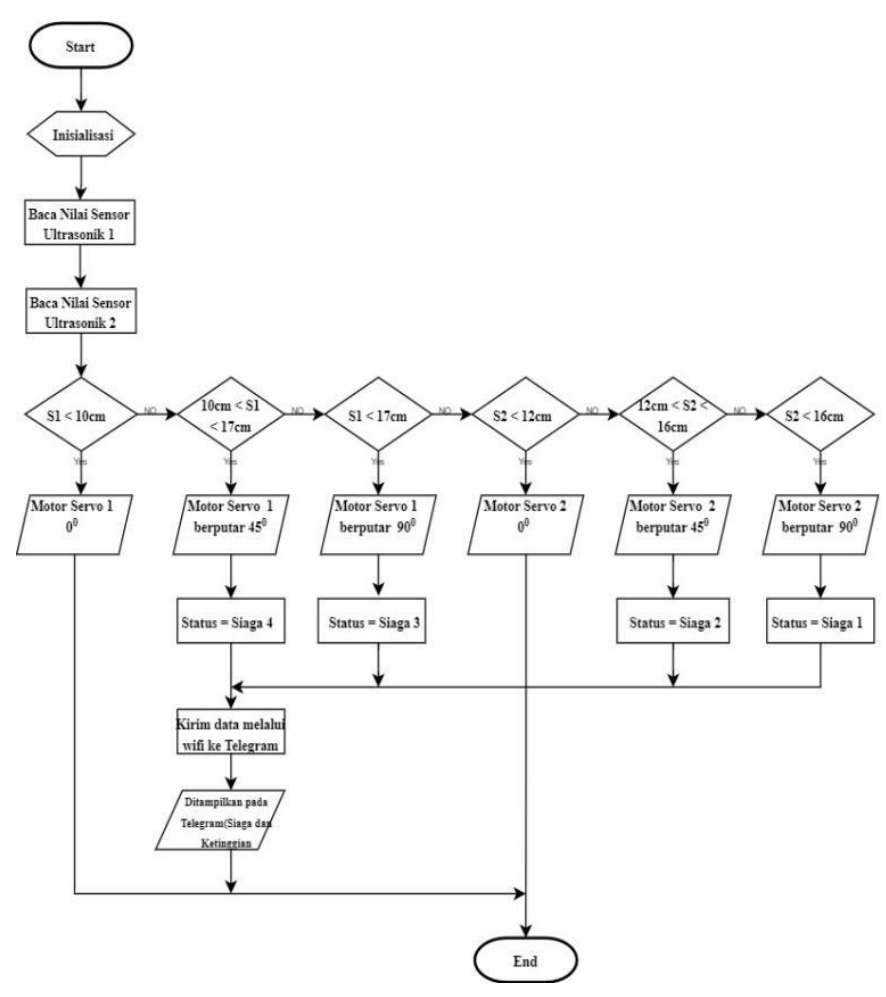

Gambar 6. Flowchart Sistem

\section{Prinsip Kerja Alat}

Pada saat suplay di hidupkan, sensor ultrasonik bersiap untuk membaca level ketinggian air, jika mencapai pada tinggi tertentu maka mikrokontroler NodeMCU akan mengirim status ketinggian serta siaga 1 atau 4 pada aplikasi android. Saya membagi menjadi dua kondisi pada penampungan pertama yaitu ketika ketinggian air 
mencapai $10 \mathrm{~cm}$, motor servo akan membuka $45^{\circ}$ dan pintu terbuka setengah serta mengirimkan status Siaga 4 dan kemudian jika air sudah mencapai ambang batas yaitu ketinggian $17 \mathrm{~cm}$ motor servo akan membuka pintu $90^{\circ}$ atau seluruhnya maka air akan mengalir ke penampungan selanjutnya dan mengirimkan notifikasi pada Telegram yaitu Siaga 3 .

Di penampungan kedua, debit air yang sudah mencapai $12 \mathrm{~cm}$ motor akan terbuka $45^{\circ}$ maka pintu terbuka setengah air akan mengalir ke penampungan terakhir serta jika debit air sudah melebihi batas $16 \mathrm{~cm}$, pintu akan terbuka sepenuhnya. Pada penampungan terakhir, debit air yang sudah ditampung di penampungan pertama dan kedua akan mengalir sungai atau penampungan terakhir pada rancang bangun alat ini.

Pada Pintu 1 jika ketinggian mencapai $10 \mathrm{~cm}$ aplikasi akan mengirim notifikasi siaga 4, ketinggian $17 \mathrm{~cm}$ akan mengirim siaga 3, dan Pintu 2 ketinggian $12 \mathrm{~cm}$ siaga 2 dan terakhir ketinggian $16 \mathrm{~cm}$ notifikasi siaga 1 akan muncul pada aplikasi Telegram dan meminta warga yang bermukim di sekitaran sungai untuk mengungsi.

\section{Perancangan Hardware}

Merupakan suatu proses tahapan dalam pembuatan perangkat keras atau mekanik alat, perancangan ini brtujuan untuk mengurangi tingkat kesalahan dalam pembuatan perangkat keras sehingga mendapatkan hasil yang maksimal.

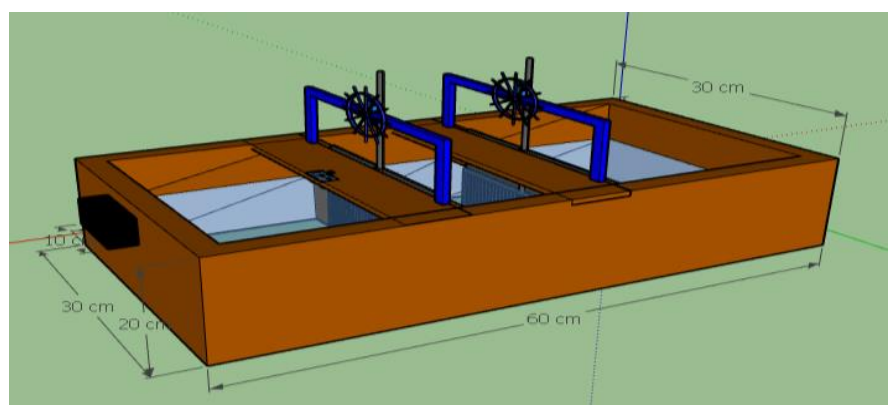

Gambar 7. Tampak Mekanik Alat

\section{Perancangan Software}

Dalam perancangan alat ini menggunakan aplikasi Arduino IDE yang merupakan bawaan dari Arduino itu sendiri. Dan untuk menggunakan nya port NodeMCU di hubungkan terlebih dahulu ke port laptop atau komputer, program di buat menggunakan bahasa $\mathrm{C}$.

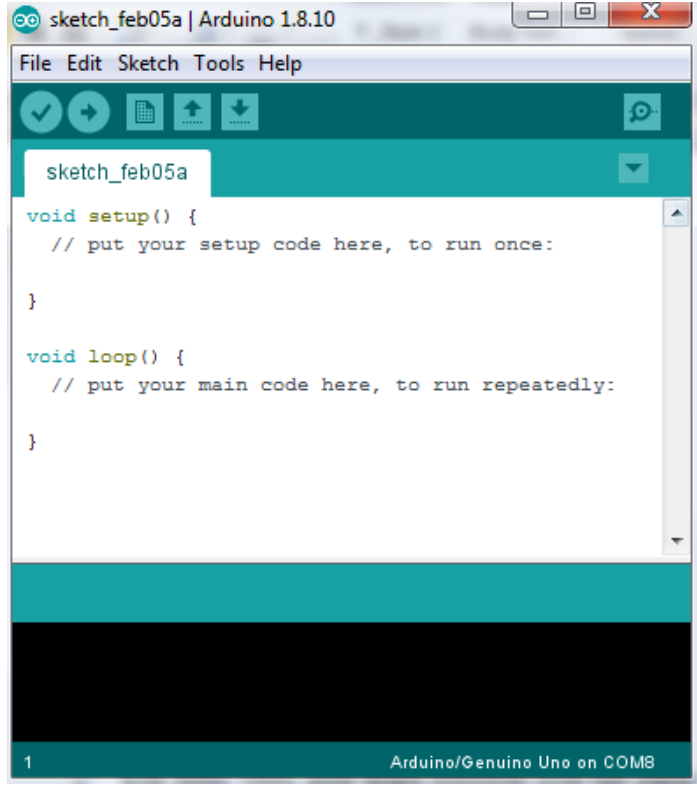

Gambar 8. Tampilan Software Arduino

\section{Rangkaian Keseluruhan}

Skematik rangkaian keseluruhan pada rancang bangun alat ini mumpunyai sistem yang terdiri dari dua Sensor Ultrasonik dan dua Motor Servo dan LCD sebagai penampilan data, yang nanti nya akan diproses dan dikontrol melalui NodeMCU, kemudian akan mengirim pesan status dan siaga pada aplikasi Telegram seperti yang terlihat pada Gambar 9, serta disuplai dengan catu daya 5 volt.

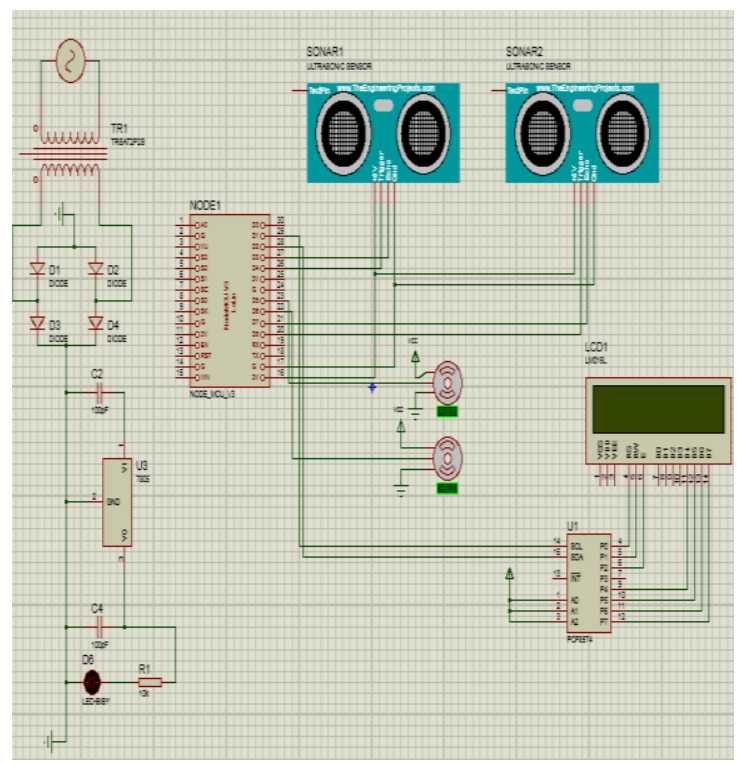

Gambar 9. Rangkaian Keseluruhan 


\section{HASIL DAN PEMBAHASAN}

Pada pembuatan Tugas Akhir ini menggunakan beberapa komponen dimana semua komponen tersebut berpusat pada NodeMCU ESP8266 sebagai pusat kendali dan juga sebagai perangkat Internet of Things (IoT). Pengujian pada perangkat keras dilakukan dengan membandingkan hasil pembacaan sensor dengan hasil pengukuran alat.

Gambar di bawah ini merupakan hasil dari perancangan alat yang akan digunakan sebagai miniatur bendungan pada tugas akhir ini.

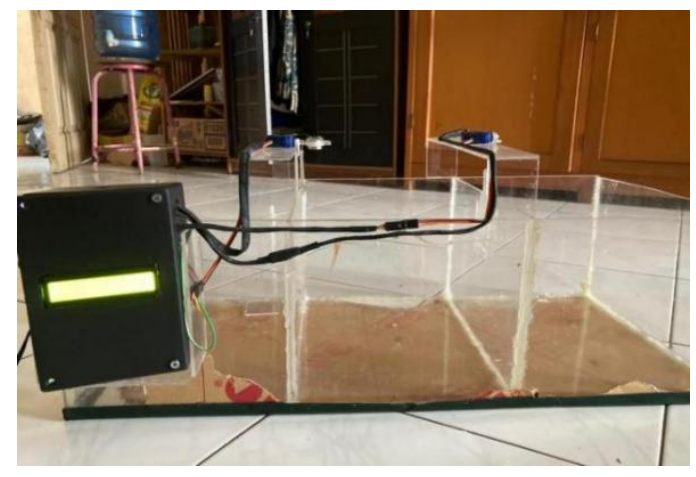

\section{Gambar 10. Rancangan Alat Tampak Depan} (Sumber : Dokumentasi Pribadi)

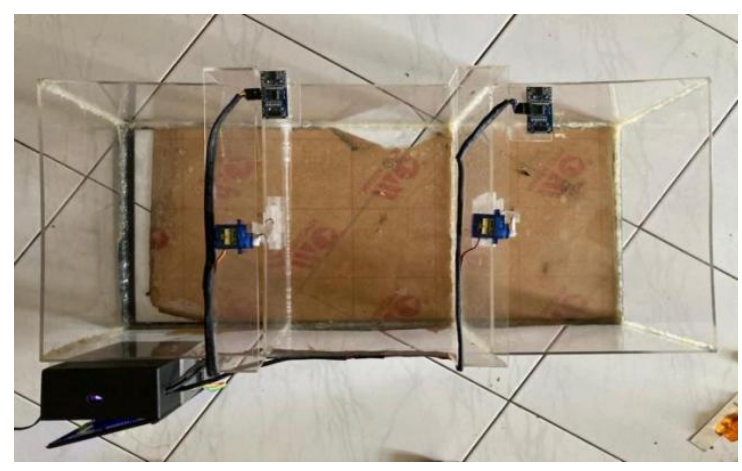

Gambar 11. Rancangan Alat Tampak Atas (Sumber : Dokumentasi Pribadi)

\section{Pengujian Sensor Ultrasonik}

Percobaan ini untuk melihat apakah sensor berfungsi dengan baik saat membaca ketinggian air, ultrasonik HCSR04 memiliki prinsip saat pulsa trigger dikirimkan pada sensor dan dipancarkan melalui transmitter kemudian mengirimkan gelombang ultrasonik, dan disaat bersamaan gelombang yang terkena objek memantulkan gelombang tersebut kembali pada sensor receiver pada sensor ultrasonik akan mempresentasikan waktu lamanya gelombang dipancarkan dan diterima menjadi jarak.

Pengujian sensor ultrasonik HC-SR04 adalah dengan cara melakukan pengukuran secara manual yaitu dengan bantuan penggaris dan juga secara digital yaitu dengan melakukan pemprograman terhadap sensor yang di tampilkan pada layar Lcd. Tujuan dari pengujian tersebut adalah untuk mengetahui tingkat keakuratan sensor dalam membaca jarak, maka hasil yang didapatkan berdasarkan percobaan tersebut adalah ke akurasian sensor sangat baik. Gambar 12 merupakan pengujian ketinggian air dengan dengan bantuan penggaris

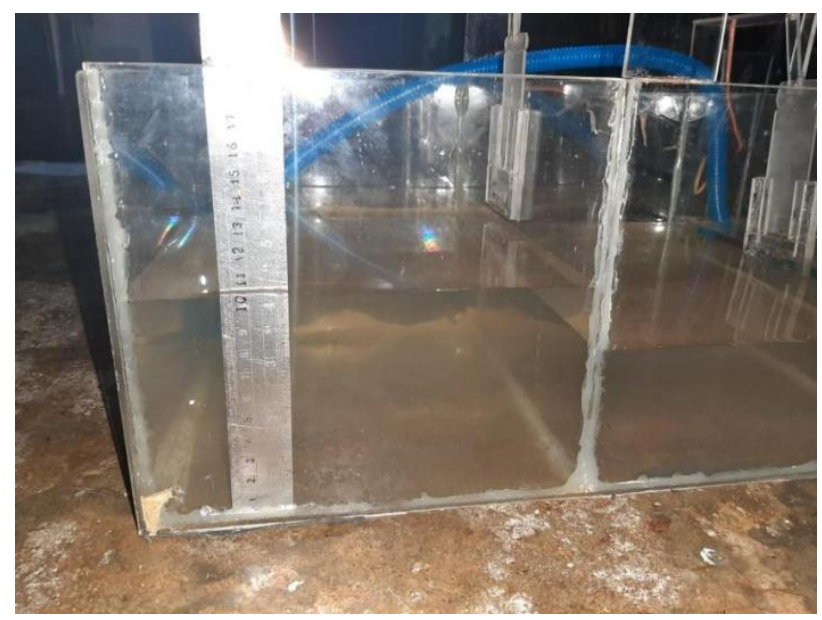

\section{Gambar 12. Pengukuran Dengan Penggaris} (Sumber : Dokumentasi Pribadi)

Dan pada gambar 13 adalah pengukuran ketinggian air dengan sensor ultrasonik yang ditampilkan pada LED.

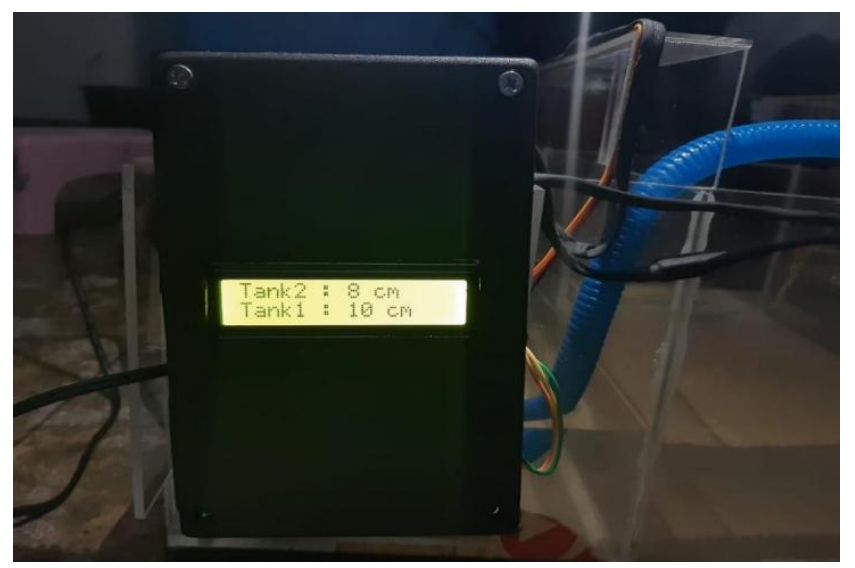

\section{Gambar 13. Pengukuran Digital Ditampilkan Pada LED} (Sumber : Dokumentasi Pribadi)

Setelah dilakukan pengujian menggunakan sensor dan penggaris kemudian digunakan untuk mengetahui berapa error dari pengukuran pada pintu 1 dan pintu 2, dan dapat dilihat bahwan penguran sangat akurat karena pada pengukuran menggunakan penggaris dan sensor mempunyai nilai yang sama serta selanjutnya dapat dilihat pada tabel dari pengujian sensor ultrasonik. 
Tabel 3. Pengujian Pada Pintu 1

\begin{tabular}{|c|c|c|}
\hline No & $\begin{array}{c}\text { Jarak Sebenarnya } \\
\text { Pada Pintu 1 }\end{array}$ & $\begin{array}{c}\text { Jarak Pengukuran } \\
\text { Pada Sensor } \\
\text { Ultrasonik (CM) }\end{array}$ \\
\hline 1 & $10 \mathrm{CM}$ & 10 \\
\hline 2 & $17 \mathrm{CM}$ & 17 \\
\hline
\end{tabular}

Tabel 4. Pengujian Pada Pintu 2

\begin{tabular}{|c|c|c|}
\hline No & $\begin{array}{c}\text { Jarak Sebenarnya } \\
\text { Pada Pintu 2 }\end{array}$ & $\begin{array}{c}\text { Jarak Pengukuran } \\
\text { Pada Sensor } \\
\text { Ultrasonik }\end{array}$ \\
\hline 1 & $12 \mathrm{CM}$ & 12 \\
\hline 2 & $16 \mathrm{CM}$ & 16 \\
\hline
\end{tabular}

Dari hasil pengujian Sensor Ultrasonik, dapat disimpulkan sensor bekerja dengan baik sesuai yang sudah di program.

\section{Pengujian Motor Servo}

Pengujian pada motor servo beeguna untuk mengetahui apakah mampu berjalan dengan fungsi dan setting masingmasing. Motor sevo digunakan pada alat ini sebanyak 2 buah. Motor servo pada 1 untuk membuka pintu 1 pada tank 1, dan pada motor servo 2 untuk membuka pintu pada tank 2 .

Tabel 5. Motor Servo Pada Pintu 1

\begin{tabular}{|c|c|c|c|}
\hline No & $\begin{array}{c}\text { Kondisi } \\
\text { Motor }\end{array}$ & Derajat & Pergerakan \\
\hline $\mathbf{1}$ & Level 4 & $45^{\circ}$ & $\begin{array}{c}\text { Pintu Terbuka } \\
\text { Setengah }\end{array}$ \\
\hline $\mathbf{2}$ & Level 3 & $90^{\circ}$ & $\begin{array}{c}\text { Pintu Terbuka } \\
\text { Penuh }\end{array}$ \\
\hline
\end{tabular}

Tabel 6. Motor Servo Pada Pintu 2

\begin{tabular}{|c|c|c|c|}
\hline No & $\begin{array}{c}\text { Kondisi } \\
\text { Motor }\end{array}$ & Derajat & Pergerakan \\
\hline $\mathbf{1}$ & Level 2 & $45^{\circ}$ & $\begin{array}{c}\text { PintuTerbuka } \\
\text { Setengah }\end{array}$ \\
\hline $\mathbf{2}$ & Level 1 & $90^{\circ}$ & $\begin{array}{c}\text { PintuTerbuka } \\
\text { Penuh }\end{array}$ \\
\hline
\end{tabular}

Hasil percobaan memperlihatkan bahwa motor servo pada tank 1 dan tank 2 bekerja dengan baik sehingga pengaturan yang diharapkan dan kinerja alat berjalan dengan baik. Motor servo 1 berfungsi untuk membuka pintu air pada pintu 1 dan motor sevo 2 untuk membuka pintu air pada pintu 2 .

\section{Pengujian Liquid Crsytal Display (LCD)}

Pada pengujian Liquid Crystal Display (LCD) dilakukan agar diketahui , bagaimanakah LCD menampilkan huruf atau angka dengan baik atau tidak. Pengujian LCD dengan memberikan tegangan sumber sebesar 5V DC untuk memastikan apakah LCD menyala dengan baik atau tidak.

Gambar di bawah merupakan tampilan dari LCD saat membaca ketinggian dari air dan LCD ini dapat bekerja dengan baik

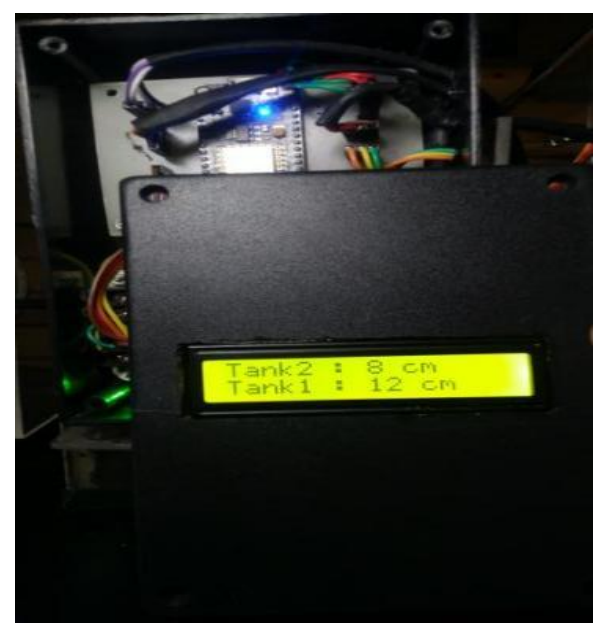

Gambar 14. Tampilan Saat Membaca Ketinggian Air (Sumber : Dokumentasi Pribadi)

Pada tampilan LCD di atas berfungsi untuk menampilkan kondisi disaat air masih stabil dan air mulai meninggi, data jarak sensor ultrasonik disaat sensor mendeteksi ketinggian air.

\section{Pengujian Aplikasi Telegram}

Pengujian Aplikasi Telegram dilakukan agar mengetahui apakah rangkaian alat yang di bangun dapat terkoneksi dengan baik pada Telegram. menggunakan modul NodeMCU yang sebelum nya telah di program dengan sambungan Wifi yang telah di persiapkan, terkoneksinya modul dengan internet dapat dilihat dari serial monitor Arduino IDE dan tampilan status pada aplikasi Telegram.

Setelah semua alat dihubungkan pada sumber serta jaringan internet atau wifi sudah dihidupkan alat akan otomatis terhubung ke perangkat wifi yang sudah dihidupkan itu, melalui sebuah program yang sebelumnya sudah diinstalkan pada NodeMCU. Dan setelah itu akan terkirim sebuah pesan yang menandakan alat siap digunakan, pesan tersebut dapat dilihat pada Telegram yang menampilkan pesan seperti pada gambar $15 \mathrm{di}$ bawah ini. 


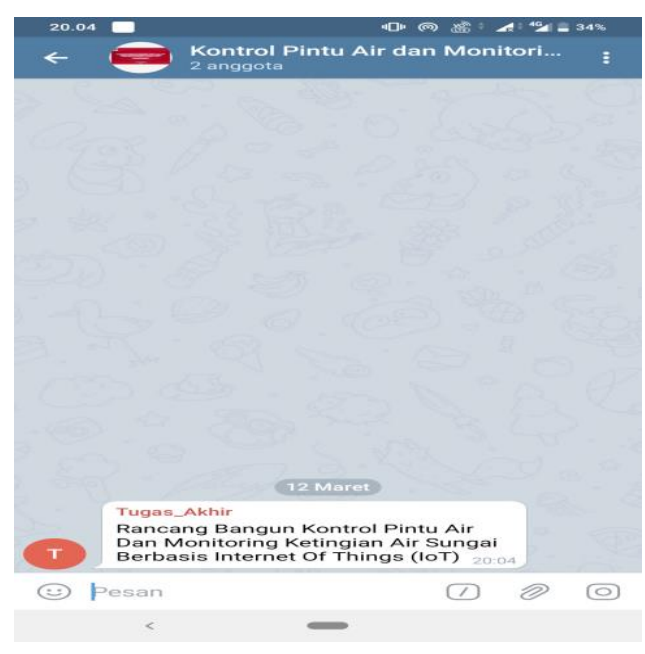

\section{Gambar 15. Tampilan Saat Terhubung ke Telegram} (Sumber : Dokumentasi Pribadi)

Akan muncul pesan pemberitahuan seperti contoh Gambar 15 di atas jika alat sudah terhubung dengan Telegram, kemudian Teleggram selanjutnya akan menerima pesan berupa level ketinggian air sesuai dengan level masing-masing pada pintu, dimana level tersebut bisa dilihat di Tabel 7 sebagai berikut.

Tabel 7. Pengujian Telegram

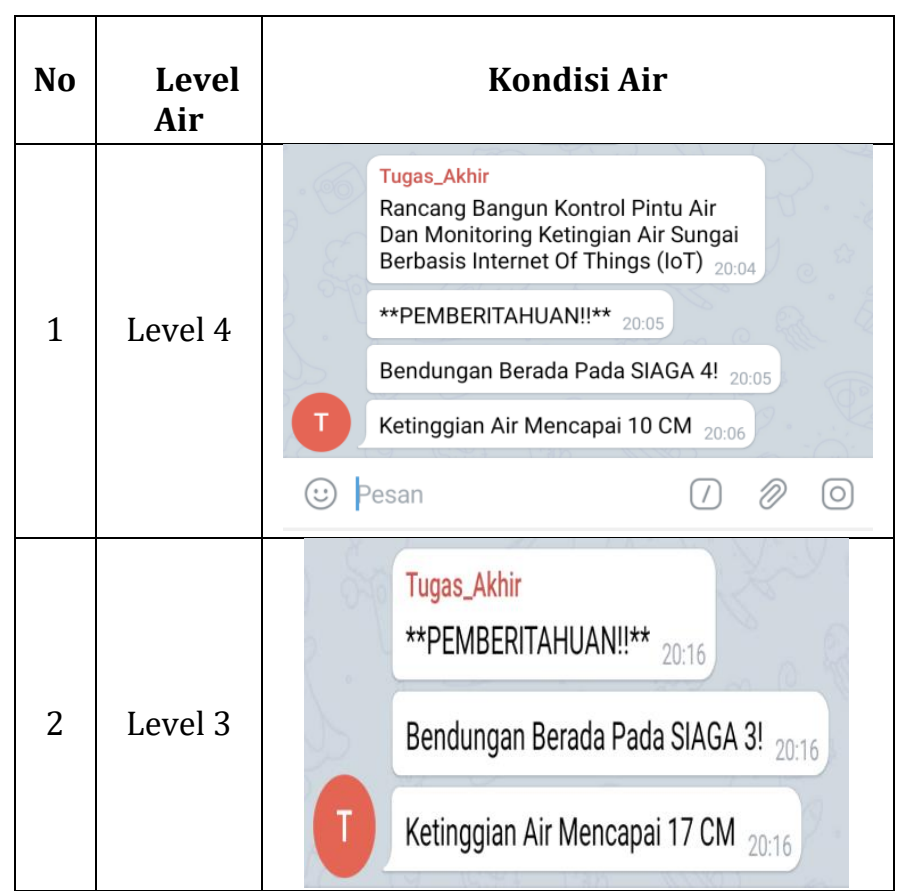

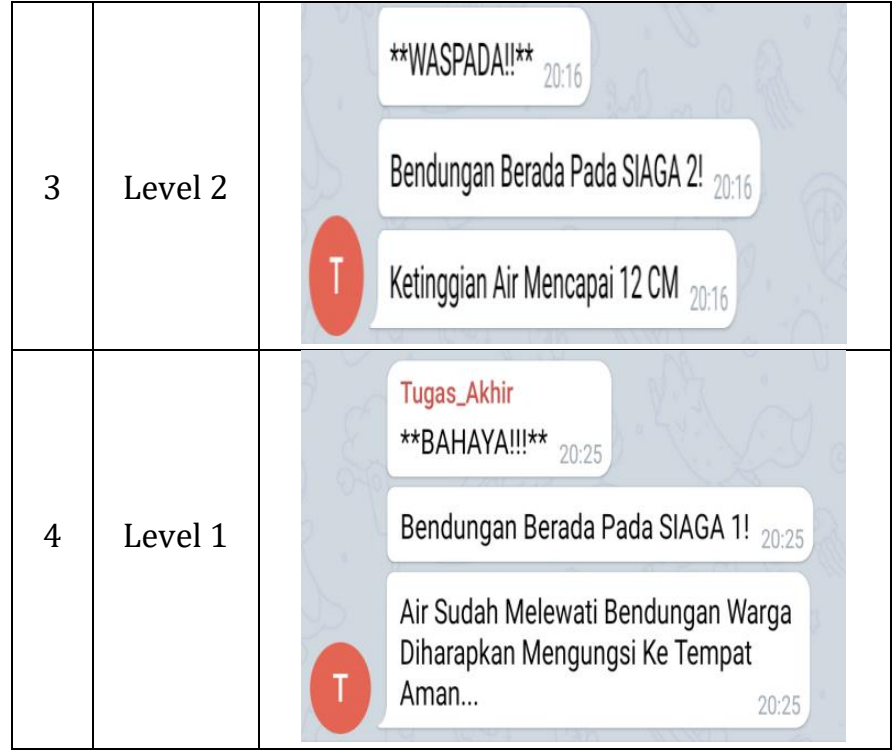

Pesan akan terus mengirimkan data ketinggian air jika sudah menyentuh pada level 4 yaitu setinggi $10 \mathrm{~cm}$, dan akan berhenti mengirimkan pesan jika ketinggian air sudah berada pada ketinggian di bawah $10 \mathrm{~cm}$, Alat akan terus terhubung ke dengan telegram jika koneksi internet tidak mati.

\section{Pengujian Keseluruhan Alat}

Dari hasil pengujian keseluruhan alat, dapat di simpulkan bahwa saat alat sudah di hidupkan maka akan otomatis terhubung ke wifi yang telah di koneksikan dengan NodeMCU. Kemudian bot Telegram akan mengirimkan pesan yang menyatakan bahwa sudah terhubung dengan wifi pada grub Telegram.

Jika air sudah mulai naik pada ketinggian $10 \mathrm{~cm}$ di Pintu 1, maka akan muncul pesan status siaga 4 pada grub Telegram, siaga 3 pada ketinggian $17 \mathrm{~cm}$. Dan jika air sudah tidak bisa di tampung lagi pada Pintu 1, air akan mengalir masuk ke Pintu 2 dan kemudian jika sudah mencapai ketinggian $12 \mathrm{~cm}$ maka akan terkirim status waspada siaga 2 di dalam grub Telegram hingga status bahaya siaga 1 jika sudah mencapai ketinggian $16 \mathrm{~cm}$.

\section{PENUTUP}

Berdasarkan pengujian terhadap pembuatan Proyek Akhir ini penulis bisa menyimpulkan bahwa keseluruhan sistem perancangan alat kontrol pintu air dan monitoring ketinggian air sungai berbasis IoT ini telah berjalan dengan baik sesuai yang telah di inginkan. Pemprograman yang telah dibuat sesuai dengan algoritma pemprograman yang dirancang dan diprogram menggunakan program aplikasi yaitu arduino IDE dengan menggunakan bahasa C.

Pada pemprograman pengukuran ketinggian air, digunakan sensor ultrasonik untuk membacanya. Rancang bangun alat yang dibuat memiliki tiga sistem yang bekerja 
secara berurutan yaitu sistem pendeteksi ketinggian air, penangulangan ketinggian air dan pengiriman informasi. Perancangan Hardware di buat dengan bentuk miniatur bendungan. Dengan memanfaatkan sensor ultrasonik untuk membaca ketinggian air serta motor servo sebagai penggerak pintu air hingga kemudian data di proses oleh NodeMCU ESP8266 lalu dikirimkan ke grub Telegram jika sudah terhubung ke wifi.

\section{REFERENSI}

[1] P. Saputra, "Prototype sistem pengaturan pintu air otomatis pada bendungan sebagai pengendali banjir," 2014.

[2] R. Sulistyowati, H. A. Sujono, and A. K. Musthofa, "Sistem Pendeteksi Banjir Berbasis Sensor Ultrasonik Dan Mikrokontroler," Inst. Teknol. Adhi Tama Surabaya, no. January, pp. 49-58, 2015.

[3] S. Sadi, "Rancang Bangun Monitoring Ketinggian Air Dan Sistem Kontrol Pada Pintu Air Berbasis Arduino Dan Sms Gateway," J. Tek., vol. 7, no. 1, 2018.

[4] H. D. Ariessanti, M. Martono, and J. Widiarto, "Sistem Pembuangan Sampah Otomatis Berbasis IOT Menggunakan Mikrokontroler pada SMAN 14 Kab.Tangerang," CCIT J., vol. 12, no. 2, pp. 229-240, 2019.

[5] L. E. García Reyes, “済無No Title No Title,” J. Chem. Inf. Model., vol. 53, no. 9, pp. 1689-1699, 2013.

[6] T. Sutikno, L. Handayani, D. Stiawan, M. A. Riyadi, and I. M. I. Subroto, "WhatsApp, viber and telegram: Which is the best for instant messaging?," Int. J. Electr. Comput. Eng., vol. 6, no. 3, pp. 909-914, 2016.

[7] M. Wicaksono, H., Kom, S., \& Kom, "Mudah Belajar Mikrokontroler Arduino. Informatika," nformatika, Bandung, vol. 1, 2017.

[8] R. Antonius, "Algoritma dan pemrograman dengan bahasa c," Andi, Yogyakarta., 2010.

[9] T. Ellison, "Datasheet NodeMCU ESP 12E."

[10] D. Minerva, R., Biru, A., \& Rotondi, "Towards a definition of the Internet of Things (IoT).," IEEE Internet Initiat., vol. 1, pp. 1-86.

\section{Biodata Penulis}

Gilang Mahendra, lahir di Padang, 5 Agustus 1997. Menyelesaikan Sarjana Sains Terapan di Jurusan Elektro Industri Fakultas Teknik, Universitas Negeri Padang.

Dr.Sukardi, M.T, lahir di Semerap Kerinci, 10 Mei 1961. menempuh pendidikan di Kerinci sejak SD, SMP dan SMA, melanjutkan kuliah Sarjana (S1) di IKIP Padang Indonesia Jurusan Pendidikan Teknik Eleltro, Magister (S2) Teknik ELektro di Institut Teknologi Bandung, dan Program Doktor (S3) bidang Pendidikan Teknologi dan Kejuruan di Pascasarjana Universitas Negeri Yogyakarta. Saat ini bertugas sebagai Dosen dan menekukni riset bidang Pendidikan Teknologi dan Kejuruan Ketenagalistrikan. 